\title{
A Photographic Assessment of Fluorosis in 10-12 Year Old Children Living in Three Areas of New South Wales Australia
}

\author{
P Mehta $^{1}$, Y Wolde ${ }^{1}$, M Kay $^{2}$, R Byun ${ }^{1,3}$, A Blinkhorn ${ }^{1, *}$ \\ ${ }^{1}$ Faculty of Dentistry, University of Sydney \\ ${ }^{2}$ Breastscreen NSW, North Sydney and Central Coast Local Health Districts \\ ${ }^{3}$ Centre for Oral Health Strategy (NSW Health)
}

${ }^{\star}$ Corresponding author: Anthony Blinkhorn, Department Population Oral Health, Mons Road, Westmead, NSW

2145 Australia; Email: anthony.blinkhorn@sydney.edu.au

Received Date: July 04 2016; Accepted Date: August 02 2016; Published Date: August 052016

Citation: P Mehta, et al. (2016) A Photographic Assessment of Fluorosis in 10-12 Year Old Children Living in Three Areas of New South Wales Australia. J Dent Oral Health 2: 1-4

\begin{abstract}
Background: Although fluoridation of public water supplies has continued to offer reductions in dental caries, concerns have been raised about fluorosis of the upper anterior teeth. Photographs were taken of the upper front teeth of children living in three areas of NSW; one area without a fluoridated public water supply, a location with an established long term fluoridation scheme and a third area that was only recently fluoridated. The photographs were randomised and scored for fluorosis by an independent examiner. The scoring was a blind assessment as a child's location would not be known.

Methods: Following an intra-oral examination for dental caries, consented children had their upper incisors cleaned with gauze, dried for 15 seconds and a photograph of their upper central incisor teeth was taken using a SOPRA Intra Oral Camera. An independent examiner scored the upper central adult incisors for fluorosis utilising the TF Index.

Results: The majority of participants in all three areas did not have any detectable fluorosis, $55.8 \%$ for the non-fluoride area, $72.1 \%$ for the established fluoride area and $66.5 \%$ for the newly fluoridated location.

The unfluoridated area had the highest proportion of children with TF scores of $3+(3.1 \%)$ compared with the established fluoridated area $(2.5 \%)$ and the newly fluoridated area (1.5\%).

Conclusions: There was no evidence of water fluoridation causing aesthetic problems in the upper central incisor teeth of 10-12 year old children in New South Wales Australia.
\end{abstract}

Keywords: Fluorosis; Water fluoridation; Children photographs; Blinded study

\section{Introduction}

New South Wales (NSW) has a long history of water fluoridation [1] and the 2007 Child Dental Health Survey [2] showed that children living in fluoridated communities had less dental caries than those not consuming fluoridated water. In addition fluorosis of the incisors was not reported as an aesthetic problem. However worldwide there is an association between dental fluorosis and the level of fluoride in the water supplies. The majority of evidence on this issue relates to countries such as parts of India and China where naturally occurring fluoride levels are up to four to five times greater than water in Australia which has community water schemes where the fluoride level is adjusted to 1ppm [3]

(C)2013 The Authors. Published by the JScholar under the terms of the Creative Commons Attribution License http://creativecommons.org/licenses/ by/3.0/, which permits unrestricted use, provided the original author and source are credited.
Never the less concern has been raised by some commentators [4] that examiner bias may be an issue when scoring fluorosis and assessing caries in comparative studies. There may indeed be an inherent bias not to score enamel defects in a known fluoridated community. One way to deal with this criticism is to photograph teeth and employ an independent examiner, who has no knowledge of a child's location to examine the teeth for fluorotic lesions. If the photographs are randomised it is possible to argue that a blinded study has been undertaken, as the examiner will be unaware of the level of fluoride in each participant's local water supply.

Photographs have been used before to assess fluorosis [5-7] and have been shown to be a useful tool. The opportunity arose to utilise photographs to record fluorosis in different areas of NSW, as a study was underway to monitor a new fluoridation scheme in the Local Government Area (LGA) of Gosford (NSW). Two other areas were included in the 
research study the Wyong Local Government Area which has been fluoridated for over forty years and the unfluoridated Shires of Ballina and Byron Bay. Children aged 10-12 years living in the three areas, whose parents consented, received a dental examination in School. In addition, as part of the project, the children had all their upper central incisors photographed so that enamel defects could be recorded.

The objective of this paper is to report on the levels of fluorosis seen on the photographs and assessed by an independent examiner using the TF index.

\section{Method}

Children aged 10-12 years from three areas of NSW who were enrolled in a study to monitor the impact of water fluoridation on dental caries [8] also had photographs taken of their two upper permanent incisors (11 and 21) after the clinical examination. This was part of an investigation to determine the potential value of using images to provide a way of blinding examiners to the geographical location of the participants, so that the fluoridation status of an area would not be known. The incisors were cleaned with gauze, and air-dried for 15 seconds before the photograph was taken. The children were examined in a supine position on a mobile dental chair. Teeth were excluded if they had tooth coloured restorations, orthodontic bands in place, only partially erupted, or presented a blurred image.

The camera used to capture the images was a SOPRA Intra Oral Camera (617 PAL) which has a built in light source. The images were stored on a laptop computer. Following the collection of the images, the study coordinator randomised the images and kept an independent master list so that the results could be linked to the three study areas. A researcher who was not involved in the main fluoridation study was recruited to score the images of the anterior teeth for Fluorosis using the TF index [9]. The diagnostic codes for the TF index are shown

0 The normal translucency of the glossy creamy white enamel remains after wiping and drying of the surface.

1 Lines are seen running across the tooth surface. Such lines are found on all part of the surface. The lines correspond to the position of the perikymata. In some cases, a slight "snow-capping" of incisal edge may also be seen.

2 The opaque white lines are more pronounced and frequently merge to form small cloudy areas scattered over the whole surface. "Snow -capping" of the incisal edges is common.

3 Merging of the white lines occurs, and cloudy areas of opacity occur over many parts of the surface. In between the cloudy areas white lines can also be seen.

4 The entire surface exhibits a marked opacity, or appears chalky white. Parts of the surface exposed to attrition or wear may appear to be less affected.

5 The entire surface is opaque, and there are losses of enamel surface of any size.

9 Non-fluorotic discolouration

$\mathrm{X}$ Not recorded/Excluded

Figure 1: Diagnostic codes for the TF index in figure 1. The data were recorded on an Excel spreadsheet. Five per cent of the images were scored to check for internal examiner consistency and another trained examiner (P.M) re-read 50 images to ensure the diagnostic standards had not altered since an initial one day training program. Intra-and inter- examiner reliability of the TF scores was determined by calculating Kappa statistics. Kappa values range from negative values to a maximum value of 1.0 when there is complete agreement. Uni-variable ordinal logistic regression was used to determine differences in enamel lesions between study sites. All the images were scored on the same computer and monitor. For the purposes of this paper only the data for the upper right central incisor will be reported as it will make the tables easier to read.

The study was approved by the State Education Research Process (SERAP) of the NSW Department of Education and Training. The Catholic Education Commission also gave permission to involve schools within their jurisdiction (SERAP number 2008052). The Sydney West Area Health Service (SWAHS) Human Research Ethics Committee granted ethical approval for the school based surveys HEREC 2008 / 314.18 (2758): All RED 08/WMEAD/57.

\section{Results}

Seven hundred and forty four images were assessed for the LGA of Gosford, 360 for the Shires of Ballina / Byron and 723 for the LGA of Wyong (Table 1). It can be seen that the majority of participants in Gosford (66.5\%) Ballina /Byron (55.8\%) and Wyong $(72.1 \%)$ did not have any detectable fluorosis (Table 1).

Table 1 also shows that 32.0 per cent $(n=238)$ of the participants in Gosford had barely detectable or perceptible fluorosis $(\mathrm{TF}=1$ or 2$)$ compared with Ballina/Byron 41.1 per cent $(n=148)$ and Wyong 25.4 per cent $(n=184)$.

\begin{tabular}{|c|c|c|c|c|c|c|c|c|}
\hline \multirow[t]{2}{*}{ Index } & \multicolumn{2}{|c|}{ Gosford } & \multicolumn{2}{|c|}{$\begin{array}{l}\text { Ballina / } \\
\text { Byron }\end{array}$} & \multicolumn{2}{|c|}{ Wyong } & \multirow{2}{*}{\begin{tabular}{|l|} 
Total \\
Freq
\end{tabular}} & \multirow[b]{2}{*}{$\begin{array}{l}\text { Per- } \\
\text { cent }\end{array}$} \\
\hline & Freq & $\begin{array}{l}\text { Per- } \\
\text { cent }\end{array}$ & Freq & $\begin{array}{l}\text { Per- } \\
\text { cent }\end{array}$ & Freq & $\begin{array}{l}\text { Per- } \\
\text { cent }\end{array}$ & & \\
\hline 0 & 495 & 66.5 & 201 & 55.8 & 521 & 72.1 & 1217 & 66.6 \\
\hline 1 & 194 & 26.1 & 102 & 28.3 & 147 & 20.3 & 443 & 24.2 \\
\hline 2 & 44 & 5.9 & 46 & 12.8 & 37 & 5.1 & 127 & 7 \\
\hline 3 & 11 & 1.5 & 11 & 3.1 & 16 & 2.2 & 38 & 2.1 \\
\hline 4 & 0 & 0 & 0 & 0 & 2 & 0.3 & 2 & 0.1 \\
\hline Total & 744 & 100 & 360 & 100 & 723 & 100 & 1827 & 100 \\
\hline
\end{tabular}

Table 1: T/F scores for the upper right incisor of 10-12 year old children living in Gosford, Ballina / Byron and Wyong.

\begin{tabular}{|l|l|l|l|l|}
\hline Effect & OR & \multicolumn{2}{|l|}{$\begin{array}{l}\text { 95\% Wald Confidence } \\
\text { Limits }\end{array}$} & P value \\
\hline Gosford vs Wyong & 0.79 & 0.63 & 0.98 & 0.03 \\
\hline $\begin{array}{l}\text { Ballina / Byron vs } \\
\text { Wyong }\end{array}$ & 0.56 & 0.43 & 0.73 & $<0.01$ \\
\hline
\end{tabular}

Table 2: A comparison of T/F scores for Gosford $\mathrm{v}$ Wyong and Ballina / Byron v Wyong 
Ballina / Byron had the highest proportion (Table 1) of participants with $\mathrm{T} / \mathrm{F}$ scores of 3 and $4(3.1 \% ; \mathrm{n}=11)$ compared with Gosford $(1.5 \% ; \mathrm{n}=11)$ and Wyong $(2.5 \%, \mathrm{n}=18)$

The ordinal regression analysis (Table 2) shows that the differences between Wyong and Ballina / Byron and Wyong and Gosford are statistically significant, with the non-fluoridated community of Ballina/Byron having a higher prevalence of fluorotic lesions than Wyong, and also the newly fluoridated area of Gosford has a higher prevalence of lesions than Wyong. The number of teeth which could not be assigned a TF score was higher (Table 3) in Ballina and Byron, 11.7 per cent compared with Gosford 2.6 per cent and Wyong 3.2 per cent. There was a higher proportion $(3.0 \% ; n=23)$ of non fluorotic lesions in Wyong than in Gosford $(0.6 \% ; \mathrm{n}=5)$ and in Ballina/Byron $(0.3 \% ; n=1)$. The intra-examiner mean Kappa score was 0.76 when the repeat examinations for Fluorosis were assessed whilst the Kappa Score for inter-examiner agreement for the 50 joint assessments was 0.61 .

The intra-examiner mean Kappa score was 0.66 (95\% CI 0.54 0.77 ) when the ten percent of repeat examinations for fluorosis were compared with the original recordings. The Kappa score for the inter-examiner agreement for the 50 joint assessments with the gold standard Trainer was 0.61 (95\% CI; $0.57-0.73$ ).

\begin{tabular}{|l|l|l|l|l|l|l|}
\hline & \multicolumn{2}{|c|}{ Gosford } & \multicolumn{2}{c|}{ Ballina/Byron } & \multicolumn{2}{c|}{ Wyong } \\
\hline & $\mathrm{n}$ & $\%$ & $\mathrm{n}$ & $\%$ & $\mathrm{n}$ & $\%$ \\
\hline T/F score assigned & 744 & 96.7 & 360 & 88 & 723 & 93.8 \\
\hline Unreadable & 20 & 2.6 & 48 & 11.7 & 25 & 3.2 \\
\hline $\begin{array}{l}\text { Non-fluorotic } \\
\text { lesion }\end{array}$ & 5 & 0.6 & 1 & 0.3 & 23 & 3 \\
\hline Total & 769 & 100 & 409 & 100 & 771 & 100 \\
\hline
\end{tabular}

Table 3: The proportion of Participants who did not have a TF Score assigned to the upper right incisor by study location.

\section{Discussion}

This paper presents the results of a photographic assessment of the presence of enamel defects on the upper right central incisor of children aged 10-12 years living in three areas of NSW with different water fluoridation histories. It is not possible to assign a direct cause and effect for the presence of fluorotic lesions as there are many confounders which could influence the outcome. Never the less the photographs were scored blind to the area of residence and little difference was noted in the prevalence of enamel lesions between any of the areas, despite one location having been fluoridated for over 40 years.

The use of the camera enabled the T/F scores to be recorded blind to a participant's area of residence. The examiner was not aware of whether an individual image came from a fluoridated or unfluoridated area. This is important as critics of fluoridation research argue that there is an inherent bias towards finding positive results from any fluoride investigation. The results from this study cannot be considered to have a problem with location bias, which is the most positive benefit. The major issue associated with using cameras as a diagnostic tool is the time factor. The screening examination takes longer because of the need to carefully position the participant so as to capture a readable image and then there is the time spent examining the pictures at a central location. Using cameras for all dental surveys may well not be economically feasible, but there could be a place for this technique in population based fluoridation research.

The teeth were cleaned with gauze and then dried with compressed air for 15 seconds, before being photographed. This is a somewhat artificial situation as teeth exist in a moist environment. However photographing teeth wet can compromise the quality of the image and minor fluorotic lesions can be missed when the enamel surface is wet, however drying does highlight enamel defects [10]. The SOPRA camera gave a good crisp image and proved to be robust and reliable in the field. The software is well written and examiners did not find it difficult to save images and export them to the study laptop computers. The inter-examiner agreement between the independent researcher and the trainer was fair (Kappa 0.61) and reflects issues with the T-F index [11] when it comes to deciding on the difference between developmental anomalies, white spots and fluorosis. However the independent examiner did remain relatively consistent when undertaking the repeat examinations (Kappa 0.76).

The levels of fluorosis recorded at T/F 3 and above were low for all areas and fluoridated Wyong did not match the fluorosis diagnosis of $\mathrm{T} / \mathrm{F} 3+$ of 7 percent reported in a photographic study in the fluoridated city of Newcastle UK[12]. A potential weakness of our study is that fluorosis was only measured in the permanent central incisors, because it is more straightforward to gain reasonable images of these teeth.

The NSW study also provides information in the three areas on how fluoride influences the early maturation of tooth enamel on the upper permanent incisors for both water fluoridation and fluoride toothpaste $[11,13]$. Reporting on the whole dentition is difficult but clearly aesthetics is one of the most important parameters, hence the focus on the upper front teeth. However the finding that the fluoridated Local Government Area of Wyong has a smaller proportion of T/F3+ scores than the shires of Ballina/Byron which is not fluoridated is an interesting result. This difference may well be due to non-response bias, as the country shires had a lower positive consent rate than the two Central Coast LGA's. The smaller proportion of T/F 3+ scores in Gosford will not have been influenced by the recent addition of fluoride to the public water supplies in 2008 because the children in our study were 10-12 years of age, and enamel maturation for the central incisors is nearly complete by around four years of age. So our concerns about non response bias are not necessarily correct given the results from the newly fluoridated area.The high proportion (44.2\%) of children from unfluoridated Ballina/Byron Shires is somewhat unusual and is higher than proportions recorded by Tavener, et al. [14]. and Tabari, et al. [15] which were around 36 and 23 per cent respectively for air dried upper incisors. The study did not examine the age at which brushing with a fluoride toothpaste began, as this can impact on the prevalence of noticeable fluorosis especially if a child under four years of age swallows large amounts of toothpaste [16]. However it is unlikely that brushing behavior would be markedly different between the three study areas. The finding of most significance from this 'blinded' study is that noticeable fluorosis $(\mathrm{T} / \mathrm{F} 3+)$ is not a 
problem in any of the three areas of NSW and is not directly related to a communities' water fluoridation status. The low levels of fluorosis are supported by the NSW 2010 Teen Survey [17] which also found low levels of $3+$ TF scores in both fluoridated $(0.1 \%)$ and the unfluoridated $(2.0 \%)$ communities. In this study low levels of fluorosis recorded by the Thylstrup and Fjerskov (TF)Index [9] suggest that a more detailed assessment process may well be helpful. One potential index that could be used is Russell's Differential Diagnosis Criteria [18] to differentiate fluorotic discolouration. This study provides interesting findings and is worthy of more research on other age groups, geographical locations and the use of different assessment indicies.

\section{Conclusion}

In this study the number of noticeable fluorotic lesions of $(T / F$ $3+)$ recorded in the three NSW study areas by photographs and scored 'blind' was low and was not related to the water fluoridation status of the communities.

\section{Acknowledgements}

The majority of the expenditure was funded by the Centre for Oral Health Strategy (NSW Health), and Northern Sydney and Central Coast Area Health Service. Contributions to the cost of the cameras were provided by Colgate Palmolive (Australia) and the Australian Dental Association (NSW Branch). The research would not have been possible without the administrative skills of Mrs Cathy Davison and the secretarial assistance of Mrs Rachael Moir. The research team would like to thank the teachers, parents and children for their kind co-operation and support.

\section{References}

1) Blinkhorn A, Byun R, Johnson G, Mehta P, Kay M, et al. (2015) The dental health of primary school children living in fluoridated, pre-fluoridated and non-fluoridated communities in New South Wales Australia. BMC Oral Health 15: 19.

2) Centre for Oral Health Strategy NSW (2009) The New South Wales Child Dental Health Survey 2007

3) NHMRC (2007) A Systematic Review of the Efficacy and Safety of Fluoridation. National Health and Medical Research Council

4) McDonagh MS, Whiting PF, Wilson PM, Sutton AJ, Chestnutt I, et al. (2000) Systematic Review of water fluoridation. British Medical Journal 321: 855-859.

5) Cochran JA, Ketley CE, Sanches L, Mamai-Homata E, Oila A-M, et al. (2004) A standardized photographic method for evaluating enamel opacities including fluorosis, Community Dentistry Oral Epidemiology 32: 19-27.

6) Martins CC, Chalub L, Lima-Arsati YB, Almeida-Pordeus I, Martins ( 2009) Agreement in the diagnosis of dental fluorosis in central incisors performed by a standardized photographic method and clinical examination. Cad SaudePublica 25: 1017-1024.

7) Wong HM, McGrath C, Lo ECM, King NM (2005) Photographs as a means of assessing developmental defects of enamel. Community Dentistry Oral Epidemiology 33:438-446.

8) Blinkhorn A, Byun R, Mehta P, Kay M.(2015 ) A Four year assessment of a new Water Fluoridation scheme in New South Wales, Australia. International Dental Journal Jun 65: 156-163.

9) Fejerskov O, Manji F, Baelum V (1998) Dental Fluorosis: a handbook for health workers. Copenhagen Munksgaerd.
10) Rozier RG (1994) Epidemiologic indicies for measuring the clinical manifestations of dental fluorosis: overview and critique. Advances in Dental Research 8: 39-55.

11) McGrady MG, Ellwood RP, Maguire A, Goodwin M, Boothman N, et al. (2012) The association between social depreviation and the prevalence and severity of dental caries and fluorosis in populations with and without water fluoridation. BMC Public Health 12:1122.

12) Evans RW, Darvell BW ( 1995) Refining the estimate of the critical period for susceptibility to enamel fluorosis in human maxillary central incisors. J Public Health Dentistry 55: 238-249.

13) Whelton HP, Ketley CE, McSweeney F, O’Mullane DM ( 2004) A review of fluorosis in the European Union, prevalence risk factors and aesthetic issues. Community Dentistry Oral Epidemiology; 32 :9-18.

14) Tavener JA, Davies GM, Davies RM, Ellwood RP (2004) The prevalence and severity of fluorosis and other developmental defects of enamel in children who received free fluoride toothpaste containing either 440 or $1450 \mathrm{ppm}$ from the age of 12 months. Community Dental Health 21: 217-223.

15) Tabari ED, Ellwood RP, Rugg-Gunn AJ, Evans DJ, Davies RM (2000) Dental Fluorosis in permanent incisor teeth in relation to water fluoridation, social deprivation and toothpaste use in infancy. British Dental Journal 189: 216-220.

16) Holt RD, Morris CE, Winter GB, Downer MC.( 1994) Enamel opacities and dental caries in children who used a low fluoride toothpaste between 2-5 years of age. International Dental Journal 44: 331341 .

17) The Centre for Oral Health Strategy. NSW Ministry of Health (2013) The New South Wales Teen Dental Survey 2010. Sydney NSW Ministry of Health.

18) Russell AL (1961) The differential diagnosis of fluoride and non fluoride enamel opacities. Journal of Public Health Dentistry 21: 143 146.

\section{Submit your manuscript to a JScholar journal} and benefit from:

ฯ Convenient online submission

ฯ Rigorous peer review

ๆ Immediate publication on acceptance

ब Open access: articles freely available online

I High visibility within the field

ๆ Better discount for your subsequent articles

Submit your manuscript at http://www.jscholaronline.org/submit-manuscript.php 